Plant Tissue Cult. \& Biotech. 20(1): 47-53, 2010 (June)

$\overline{\text { PTC\&B }}$

\title{
Efficient Plant Regeneration from Shoot Apices of Pearl Millet (Pennisetum americanum (L.) Leeke)
}

\author{
Y. Varalaxmi, A. Vijayalakshmi, K. Ravi Kumar, T. Vijayalakshmi \\ and M. Maheswari* \\ Division of Crop Sciences, Central Research Institute for Dryland Agriculture, \\ Santhoshnagar, Hyderabad, India
}

Key words: Pearl millet, Efficient, Plant regeneration, Shoot apices

\begin{abstract}
An efficient and rapid regeneration protocol was developed from shoot tip explants of Pennisetum americanum (L.) Leeke variety WC-75. MS supplemented with low concentration of 2,4-D and $\mathrm{Kn}$ was most effective in producing embryogenic calli. Maximum regeneration potential of 40 shoots per calli were obtained when transferred to regeneration medium containing $1.0 \mathrm{mg} / \mathrm{l} \mathrm{Kn}$. Shoots developed were efficiently rooted within 15 days on the medium containing NAA. Over $90 \%$ of rooted plants were fertile after transfer to a net house.
\end{abstract}

\section{Introduction}

Pearl millet (Pennisetum americanum (L.) Leeke) is an important staple food grain in India and Western Africa and is widely cultivated in semi-arid regions especially under low soil fertility and harsh climatic conditions. Pearl millet is highly susceptible to downy mildew disease caused by the fungus Sclerospora graminicola (Sacc.) Schroet., which can cause up to 70\% reduction in yield. Insect pests also inflict severe damage in field and during storage. Therefore, improvement of pearl millet crop will have a great effect on socio-economic status of the people in rural areas (Arockiasamy et al. 2001), where it is widely cultivated. Traditional breeding has been the main avenue for crop improvement in pearl millet until recently. The objectives of improvement include better utilization of natural resources, development of resistance against biotic and abiotic stresses and improvement of quality for wider consumer acceptance. However, improvement of millets using biotechnology has largely been unattempted, due not only to economic or regional considerations but also nonavailability of robust and reproducible regeneration protocols (Kothari et al. 2005). An efficient regeneration system is often a pre-requisite for application of

*Author for correspondencer. <mmaheswari@crida.ernet.in>. 
biotechnological applications like gene transfer. Successful regeneration in pearl millet has been reported from immature embryos (Vasil and Vasil 1982) and immature inflorescences (Pius et al. 1993, Mythili et al. 1997). However, production of these explants is a space, time and labour consuming task. Explants such as mature embryos from seed (Botti and Vasil 1983), shoot apices or meristems (Mythili et al. 2001, Devi et al. 2000) are definitely more convenient. Reports of successful callus induction and plant regeneration from shoot apices in majority of cereal crops, including maize (Zhong et al. 1992), wheat (Ahmad et al. 2002), rice (Nhut et al. 2000), barley (Ganeshan et al. 2003), sorghum (Maheswari et al. 2006) and millets (Devi et al. 2000) provide evidence for developmental plasticity of the apical shoots. Shoot apical meristems of cereals are also easily amenable for shoot regeneration, transformation studies and is highly advantageous for rapid regeneration into mature plants (Sticklen and Oraby 2005).

In this paper, we report a highly efficient, rapid season-independent protocol for plant regeneration from shoot apices of pearl millet.

\section{Materials and Methods}

Seeds of pearl millet (Pennisetum americanum) (L.) Leeke cv. WC-75 were obtained from Dr. K.N. Rai, ICRISAT (Patancheru, Andhra Pradesh). Surface sterilization of the seeds was done by rinsing them in $70 \%$ alcohol for one min followed by $0.1 \%$ mercuric chloride for two min. The seeds were then washed in sterile distilled water five times and were aseptically germinated on wet cotton in culture bottles (50 seeds per bottle) in the dark at $25^{\circ} \mathrm{C}$. After $48 \mathrm{hrs}$ of germination, $3 \mathrm{~mm}$ sections of shoot apices were carefully dissected from the germinating seedlings. The sections were then cultured on MS supplemented with various concentrations of 2,4-D (0.50, 0.75, 1.0, 2.0 and $3.0 \mathrm{mg} / \mathrm{l})$ and $\mathrm{Kn}$ $(0.25$ and $0.50 \mathrm{mg} / \mathrm{l})$ and solidified with $0.8 \%$ agar. Ten explants were horizontally placed in the medium in each Petri dish and were maintained in dark at $25 \pm 1^{\circ} \mathrm{C}$. Callus initiation was observed typically ten days after inoculation. Culture responses were recorded, based on the callus diameter and fresh weight. The calli were subcultured at 13 days intervals and at the time of each transfer leaves, coleoptiles and elongated shoots were continuously removed from the explant so as to expose the shoot apices. Twenty five days after inoculation cultures were transferred to regeneration medium containing $\mathrm{Kn}(1.0 \mathrm{mg} / \mathrm{l})$. The cultures were then grown in light $\left(85 \mu \mathrm{mol} / \mathrm{m}^{2} / \mathrm{s}\right)$ under a 12 hrs photoperiod for 20 days. The relative efficiency of multiple shoot regeneration was evaluated by visually scoring the shoots 15 days after subculturing. Regeneration frequency was calculated based on the ratio of calli showing shoot emergence to the total number of calli in percentage. Regenerated 
plantlets were then transferred to rooting medium containing NAA $(1 \mathrm{mg} / \mathrm{l})$ and maintained for 15 days. Subsequently plantlets with well-developed root system were transferred to a substrate comprising $1: 1$ peat and soil rite for further development in green house. Each treatment had three replications and each experiment was repeated at least twice.

\section{Results and Discussion}

Initial culturing of the shoot apex explants on MS containing 2,4-D in combination with $\mathrm{Kn}$ resulted in creamish white calli (Fig. 1a). Subsequently embryogenic, compact, nodulated callus, developed by two weeks (Fig. 1b). Induction of embryogenic callus was also reported at a 2, 4-D concentration of around $2.0 \mathrm{mg} / \mathrm{l}$ (Vasil and Vasil 1981, Taylor and Vasil 1991, O' Kennedy et al. 2004). No callusing response was observed when explants were cultured on MS without any plant growth regulators.
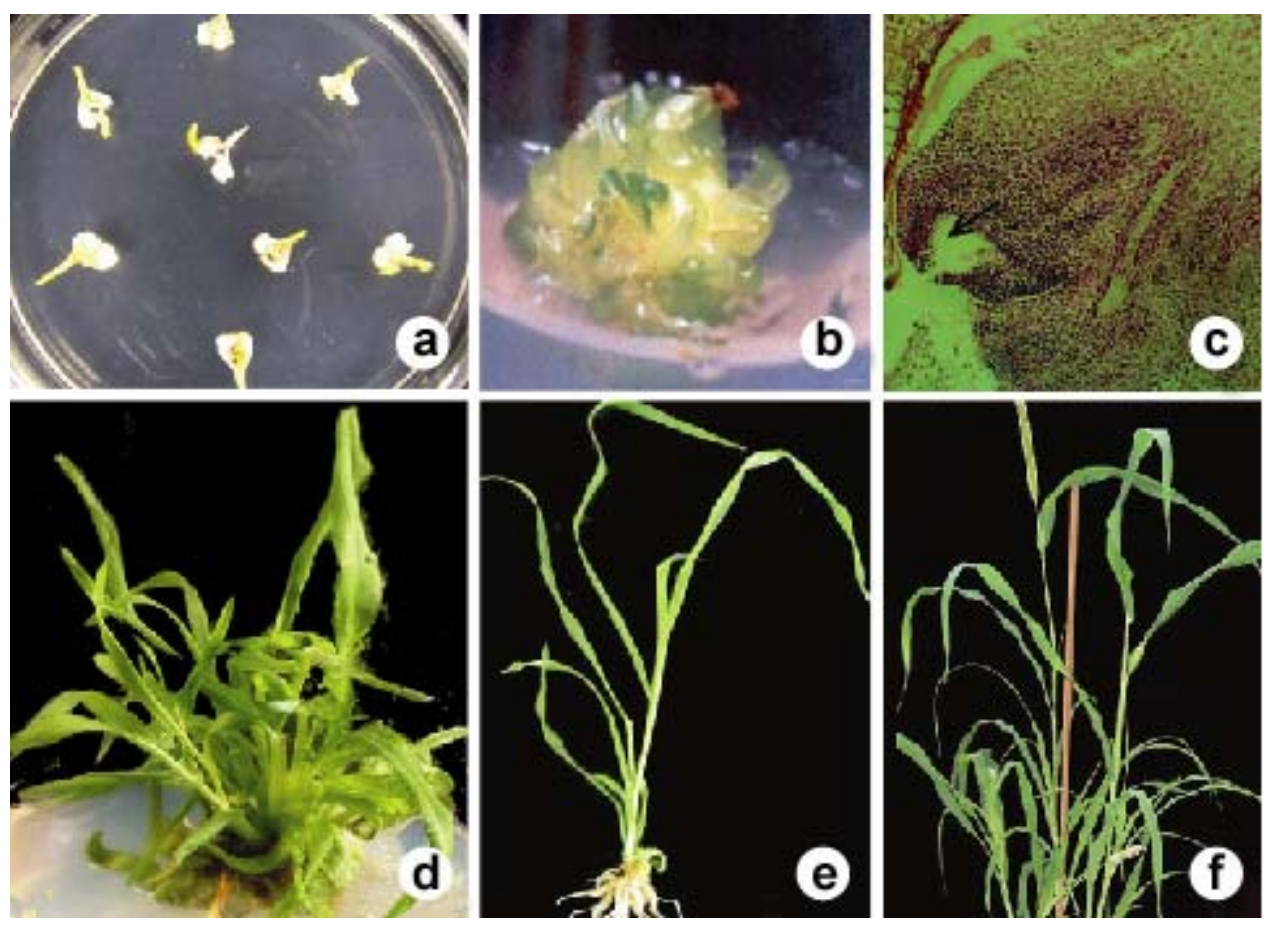

Fig. 1. Shoot regeneration from apical meristems in P. americanum. (a). Explants on the callus induction medium. (b). Twenty five days old calli on induction medium. (c). De novo formation of shoot buds at initial stage of development. (d). Regeneration of shoots. (e). Rooting (f). Regenerated plants growing in pot.

In general, the callus induction frequency was $100 \%$ in MS containing 2,4-D in combination with $0.25 \mathrm{mg} / \mathrm{Kn}$, while it ranged from $85-95 \%$ on all other media combinations tested. The largest callus diam $(0.93 \mathrm{~cm})$ and maximum 
fresh weight $(0.50 \mathrm{~g})$ of calli were recorded on 2,4-D at $0.5 \mathrm{mg} / \mathrm{l}$ concentration in combination with $0.25 \mathrm{mg} / \mathrm{l} \mathrm{Kn}$, compared to all other combinations (Table 1). But it is to be noted that this high concentration of 2,4-D in particular led to complete inhibition of shoot regeneration at a later stage when cultured on regeneration medium.

Table 1. Effect of 2,4-D and $\mathrm{Kn}$ on callus induction in shoot tip derived cultures of pearl millet cv. WC-75.

\begin{tabular}{|c|c|c|c|}
\hline \multicolumn{2}{|c|}{ Growth regulators $(\mathrm{mg} / \mathrm{l})$} & \multirow{2}{*}{$\begin{array}{c}\text { Callus diam } \\
(\mathrm{cm})\end{array}$} & \multirow{2}{*}{$\begin{array}{c}\text { Fresh wt. of callus } \\
(\mathrm{g})\end{array}$} \\
\hline $2,4-\mathrm{D}$ & Kn & & \\
\hline 0.50 & 0.25 & $0.93 \pm 0.01$ & $0.503 \pm 0.03$ \\
\hline 0.50 & 0.50 & $0.83 \pm 0.02$ & $0.401 \pm 0.02$ \\
\hline 0.75 & 0.25 & $0.73 \pm 0.01$ & $0.436 \pm 0.04$ \\
\hline 0.75 & 0.50 & $0.76 \pm 0.03$ & $0.461 \pm 0.04$ \\
\hline 1.00 & 0.25 & $0.80 \pm 0.00$ & $0.464 \pm 0.02$ \\
\hline 1.00 & 0.50 & $0.73 \pm 0.01$ & $0.416 \pm 0.02$ \\
\hline 2.00 & 0.25 & $0.76 \pm 0.01$ & $0.388 \pm 0.01$ \\
\hline 2.00 & 0.50 & $0.90 \pm 0.01$ & $0.383 \pm 0.04$ \\
\hline 3.00 & 0.25 & $0.80 \pm 0.01$ & $0.465 \pm 0.04$ \\
\hline 3.00 & 0.50 & $0.70 \pm 0.01$ & $0.411 \pm 0.05$ \\
\hline
\end{tabular}

Data on all the parameters were recorded two weeks after culture.

Light microscopic observation of 25 days old callus growing on regeneration medium clearly revealed initiation of de novo shoot buds from callus cultures (Fig. 1c).

Inclusion of $\mathrm{Kn}$ in callus induction medium facilitated callus growth as well as subsequent shoot regeneration. Regeneration response of the calli obtained on different combinations of 2,4-D and $\mathrm{Kn}$ was tested on $1 \mathrm{mg} / \mathrm{l} \mathrm{Kn}$. Combination of BAP $(4.43 \mu \mathrm{M})$ and $\mathrm{Kn}(4.64 \mu \mathrm{M})$ has also been reported to enhance shoot regeneration in P. glaucum (Arockiasamy et al. 2006). In present experiments, 2,4D concentrations of $0.5,0.75$ and $1.0 \mathrm{mg} / \mathrm{l}$ in combination with lower concentrations of $\mathrm{Kn}$ were very effective in obtaining a good regeneration frequency and number of shoots (Table 2). 2,4-D at a concentration of 0.75 and $0.25 \mathrm{mg} / \mathrm{l} \mathrm{Kn}$ showed highest regeneration frequency of $62.5 \%$ as well as shoot number of 40 shoots (Fig. 1d). The callus induction frequency was also $100 \%$ in the above mentioned concentration. Increased concentration of 2,4-D led to a lower regeneration frequency and shoot number. The presence of 2,4-D in the medium was definitely detrimental to chlorophyll synthesis in callus (Bhaskaran et al. 1992). Kn was able to restore chlorophyll content in callus to a certain 
extent. Thus at higher concentrations of 2,4-D in combination with $\mathrm{Kn}$ a moderate regeneration response was observed. Kn was shown to be more effective in improving the regeneration potential.

Table 2. Effect of 2,4-D and Kn on shoot tip derived calli on transferring to regeneration medium supplemented with $\mathrm{Kn}(1.0 \mathrm{mg} / \mathrm{l})$ after four weeks of culture.

\begin{tabular}{ccc}
\hline \multicolumn{2}{c}{$\begin{array}{c}\text { Growth regulators (mg/l) } \\
\text { in callus induction medium }\end{array}$} & $\begin{array}{c}\text { No. of shoots per } \\
\text { callus }\end{array}$ \\
\cline { 1 - 2 } 2,4 -D & Kn & \\
\hline 0.50 & 0.25 & $53.5 \pm 1.50$ \\
0.50 & 0.50 & $46.0 \pm 1.00$ \\
0.75 & 0.25 & $80.0 \pm 2.00$ \\
0.75 & 0.50 & $66.0 \pm 3.00$ \\
1.00 & 0.25 & $54.0 \pm 1.00$ \\
1.00 & 0.50 & $62.5 \pm 3.00$ \\
2.00 & 0.25 & $47.0 \pm 5.00$ \\
2.00 & 0.50 & $41.0 \pm 5.00$ \\
3.00 & 0.25 & $40.0 \pm 2.00$ \\
3.00 & 0.50 & $37.0 \pm 2.00$ \\
\hline
\end{tabular}

After 20 days on regeneration medium, shoot formation was observed. Shoots were green and healthy. Individual shoots were separated and transferred to the medium containing NAA $(1.0 \mathrm{mg} / \mathrm{l})$ for rooting. Roots developed within 15 days (Fig. 1e). Over $90 \%$ of rooted plantlets grew well and were fertile after transfer to the net house (Fig. 1f). The developmental morphology of these plants was similar to that of seed derived plants in the net house and they flowered normally and produced mature viable seeds.

An efficient and rapid plant regeneration protocol for pearl millet using shoot apicesis is reported here. The morphogenetic response of the shoot apices depended on the concentration of 2,4-D and $\mathrm{Kn}$ in present experiments. Lower concentrations of 2,4-D and $\mathrm{Kn}(0.75,0.25 \mathrm{mg} / \mathrm{l})$ were very effective in producing embryogenic calli which upon transfer to a higher $\mathrm{Kn}(1.0 \mathrm{mg} / \mathrm{l})$ containing medium clearly improved regeneration efficiency with nearly 40 shoots per callus. Here, regeneration system is also relatively rapid as the regenerated and rooted plantlets can be obtained within 65 - 67 days. This kind of a robust regeneration system is critical for efficient genetic transformation of pearl millet.

\section{References}

Ahmad A, Zhong H, Wang W and Sticklen MB (2002) Shoot apical meristem: in vitro regeneration and morphogenesis in wheat (Triticum aestivum L.). In Vitro Cell. Dev. Biol.-Plant 38: 163-167. 
Arockiasamy S, Prakash S and Ignacimuthu S (2001) High regenerative nature of Paspalum scrobiculatum L. an important millet crop. Curr. Sci. 80: 496-498.

Arockiasamy S, SahayaRani S, Ignacimuthu S and Melchias G (2006) Efficient protocols for in vitro regeneration of Pennisetum glaucum (L) Br. Indian J. Exp. Biol. 44: 757761.

Bhaskaran S, Rigoldi M and Smith RH (1992) Developmental potential of sorghum shoot apices in culture. J. Plant Physiol. 140: 481-484.

Botti C and Vasil IK (1983) Plant regeneration by somatic embryogenesis from parts of cultured mature embryos of Pennisetum americanum (L.) K. Schum. Z Pflanzen Physiol. 111: 319-325.

Devi P, Zhong H and Sticklen MB (2000) In vitro morphogenesis of pearl millet (Pennesetum glaucum (L.) R. Br.]: efficient production of multiple shoots and inflorescences from shoot apices. Plant Cell Reports 19: 546-550.

Ganeshan S, Baga M, Harvey BL, Rossnagel GB, Scoles GL and Chibbar RN (2003) Production of multiple shoots from the Thidiazuron treated mature embryos and leaf base / apical meristems of barley (Hordeum vulgare L.). Plant Cell Tiss. Org. Cult. 73: 57-64.

Kothari SL, Kumar S, Vishnoi RK, Kothari A and Watanabe KN (2005) Applications of biotechnology for improvement of millet crops: Review of progress and future prospects. Plant biotechnol. 22: 81-88.

Maheswari M, Jyothilakshmi N, Yadav SK, Varalaxmi Y, Vijayalakshmi A, Vanaja M and Venkateswarlu B (2006) Efficient plant regeneration from shoot apices of sorghum. Biol. Plant. 50: 741-744.

Mythili PK, Madhavi A, Reddy VD and Seetharama N (2001) Efficient regeneration of pearl millet [Pennisetum glaucum (L.) R. Br.] from shoot tip cultures. Indian J. Exp. Biol. 39: 1274-1279.

Mythili PK, Satyavathi V, Pavan Kumar G, Rao MVS and Manga V (1997) Genetic analysis of short term callus culture and morphogenesis in pearl millet Pennisetum glaucum. Plant Cell Tiss. Org. Cult. 50: 171-178.

Nhut DT, Bui VL and Tran TVK (2000) Somatic embryogenesis and direct shoot regeneration of rice (Oryza sativa L.) using thin cell layer culture of apical meristrimatic tissue. J. Plant Physiol. 157: 559-565.

O' Kennedy MM, Burger JT and Botha FC (2004) Pearl millet transformation system using the positive selectable marker gene phosphomannose isomerase. Plant Cell Reports 22: 684-690.

Pius J, George L, Eapen S and Rao PS (1993) Enhanced plant regeneration in pearl millet (Pennisetum americanum) by inhibitors and cefotaxime. Plant Cell Tiss. Org. Cult. 32: 91-96.

Sticklen MB and Oraby HF (2005) Shoot apical meristem: A sustainable explant for genetic transformation of cereal crops. In Vitro Cell. Dev. Biol.-Plant 41: 187-200.

Taylor MG and Vasil IK (1991) Histology of, and physical factors affecting, transient GUS expression in pearl millet (Pennisetum glaucum L.) R. Br. embryos following microprojectile bombardment. Plant Cell Reports 10: 120-125. 
Vasil V and Vasil IK (1981) Somatic embryogenesis and plant regeneration from tissue cultures of Pennisetum americanum x Pennisetum purpureum hybrid. Amer. J. Bot. 68: $864-872$.

Vasil V and Vasil IK (1982). Characterization of an embryogenic cell suspension culture derived from cultured inflorescences of Pennisetum americanum (Pearl millet, Gramineae). Amer. J. Bot. 69: 1441-1449.

Zhong H, Srinivasan C and Sticklen MB (1992) In vitro morphogenesis of corn (Zea mays L.): differentiation of multiple shoot clumps and somatic embryos from shoot tips. Planta 187: 483-497. 